This item was submitted to Loughborough's Research Repository by the author.

Items in Figshare are protected by copyright, with all rights reserved, unless otherwise indicated.

\title{
Evaluation of bone strength: correlation between measurements of bone mineral density and drilling force
}

PLEASE CITE THE PUBLISHED VERSION

PUBLISHER

Professional Engineering Publishing / @ IMECHE

VERSION

VoR (Version of Record)

LICENCE

CC BY-NC-ND 4.0

\section{REPOSITORY RECORD}

Ong, Fook Rhu, and Kaddour Bouazza-Marouf. 2019. "Evaluation of Bone Strength: Correlation Between Measurements of Bone Mineral Density and Drilling Force". figshare. https://hdl.handle.net/2134/5143. 
This item was submitted to Loughborough's Institutional Repository (https://dspace.lboro.ac.uk/) by the author and is made available under the following Creative Commons Licence conditions.

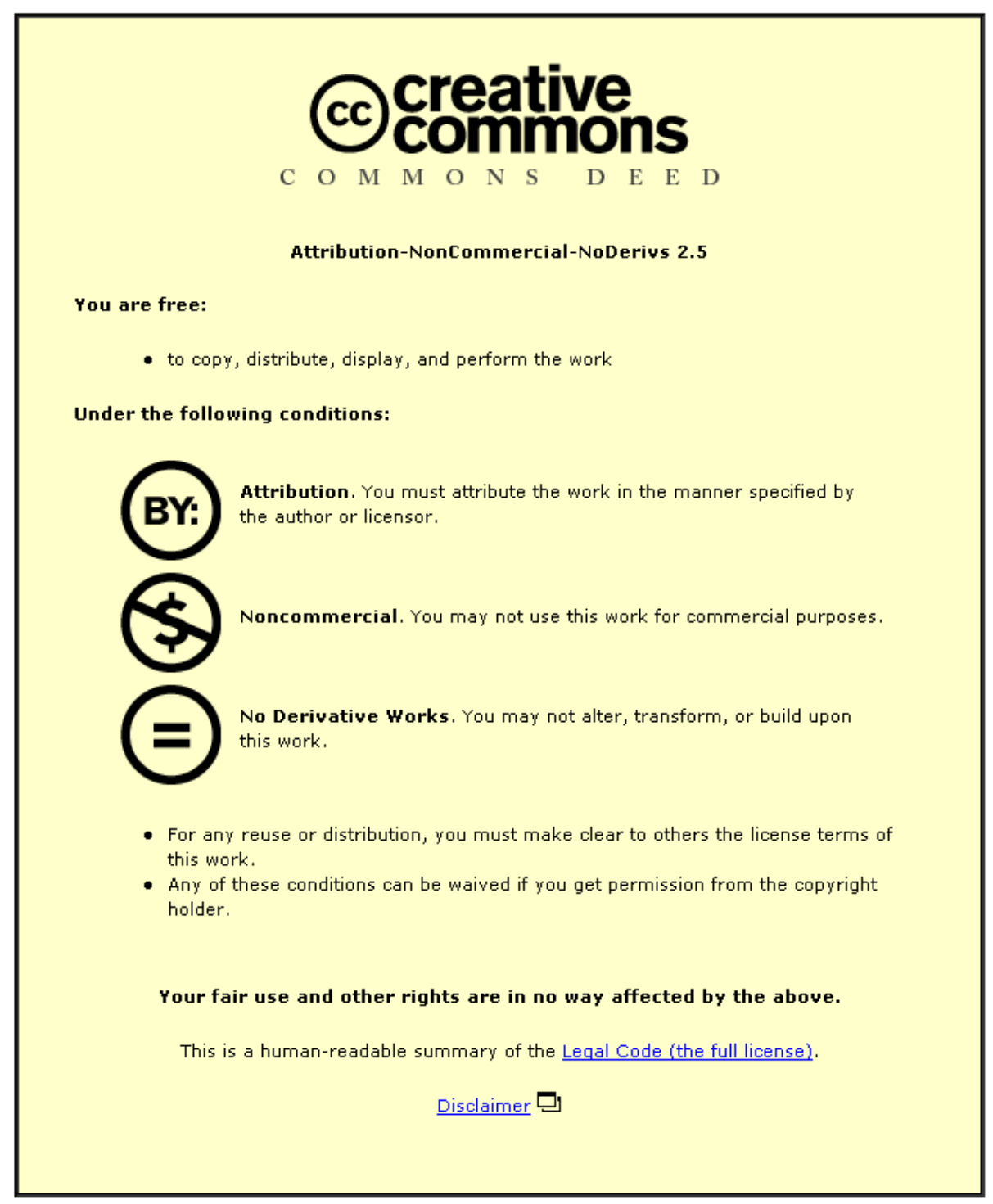

For the full text of this licence, please go to: http://creativecommons.org/licenses/by-nc-nd/2.5/ 


\title{
Evaluation of bone strength: correlation between measurements of bone mineral density and drilling force
}

\author{
F R Ong and K Bouazza-Marouf * \\ Department of Mechanical Engineering, Loughborough University, Leicestershire, UK
}

\begin{abstract}
Bone drilling is a major part of modern orthopaedic surgery which involves the internal fixation of fractured bones. The investigation of bone drilling described in this paper demonstrates the contribution of automation technology towards the study of bone strength. The aim of this preliminary investigation is to establish a relationship between bone drilling forces and measurements of bone mineral density (BMD) by dual energy X-ray absorptiometry (DXA). A linear relationship with a high coefficient of correlation has been found between average drilling forces and BMD measurements at both the greater trochanter and the femoral head of porcine femurs when drilling in the anterior-posterior (AP) direction (i.e. the direction of the DXA scan). It has also been found that in the normal drilling direction (i.e. in the cervical axis direction), which is orthogonal to the DXA scanning direction, there are similar trends between the drilling forces and BMD levels in regions where bone density is more consistent (e.g. the femoral head). The findings of this investigation indicate that analysis of bone drilling forces has the potential to provide useful information about the strength of bone.
\end{abstract}

Keywords: bone drilling, drilling force, bone strength, bone densitometry, orthopaedics

\section{NOTATION \\ $r^{2} \quad$ coefficient of correlation/determination}

\section{Abbreviations}

AP anterior-posterior

BMD bone mineral density

DXA dual energy X-ray absorptiometry

ROI region of interest

\section{INTRODUCTION}

Drilling of bone is a major part of orthopaedic surgery. However, information of drilling forces or rate of advancement is, at present, not attainable in manual drilling. Early use of this information through laboratory based investigations has been primarily for the

The MS was received on 22 December 1998 and was accepted after revision for publication on 3 August 1999.

* Corresponding author: Department of Mechanical Engineering, Loughborough University, Loughborough, Leicestershire LE11 3TU, $U K$.

H07398 C IMechE 2000 improvement of drilling performance through the design of a suitable drill bit shape and the use of optimum drilling conditions [1-4]. One of the potential benefits of such information, obtained from an automated or a mechatronic system, is a safety enhancement of the surgical drilling process, namely the detection of drill bit break-through [5, 6]. Another potential benefit is to use the drilling force measurements to estimate the strength of bone. The intended application of the proposed technique is to provide orthopaedic surgeons with information on bone quality while performing internal fixations of fractured bones. The aim is to remove the subjective evaluation of bone quality by surgeons, when bone mineral density (BMD) measurements are not available, and to allow for a quantitative bone quality evaluation to be made, during surgery. This allows the surgeon to take a decision, which may involve changing the procedure and/or recommending appropriate postoperative treatment and care, to avoid complications/ failure of the fixation. As the outcome (and the success) of the fixation can be affected by the bone quality, this information is therefore useful when the fractured bone has been affected by disease, such as osteoporosis. It will also be useful when BMD measurements have not been taken prior to the operation, especially in low-risk 
patients. Also, the proposed technique provides the surgeon with additional information, whether BMD measurements have been taken or not, about the local strength of the bone, i.e. along the drilled holes. This is useful for follow-up studies.

One method of determining bone strength is based on basic engineering principles which relate material strength to mechanical properties, structural properties and loading conditions [7]. Structural properties are intimately related to the mechanical properties. The strength of bone is normally characterized by apparent density, compressive strength and modulus of elasticity. Apparent density is the dry weight of bone per unit volume. Another method of strength evaluation is bone densitometry. This method is non-invasive, and determines in vivo the amount and the density of bone present [8]. In densitometry, bone strength is determined through bone mineral content (BMC) in $\mathrm{g} / \mathrm{cm}, \mathrm{BMD}$ in $\mathrm{g} / \mathrm{cm}^{2}$, true bone mineral density in $\mathrm{g} / \mathrm{cm}^{3}$, broadband ultrasonic attenuation (BUA) and speed of sound (SOS). The techniques used to measure BMD are dualenergy X-ray absorptiometry (DXS or DEXA) which is the most widely used technique, dual-photon absorptiometry (DPA) and single-photon absorptiometry (SPA). True mineral density is obtained from quantitative computed tomography (QCT), while quantitative ultrasound (QUS) measures BUA and SOS. Both the densitometry method and the method based on basic engineering principles have a primary aim of studying the strength of bone, especially cancellous (trabecular/spongy) bone, for the evaluation of fracture risk and bone affected by disease such as osteoporosis.

Bone consists of two basic structural components: cortical (compact) and cancellous bone. The human skeleton is represented by approximately $70-80$ per cent cortical bone and 20-30 per cent cancellous bone [9]. In general, research into bone strength has concentrated on either strength of materials (mechanical properties) or bone densitometry. The literature on the mechanical properties of both cortical and cancellous bones is well established and reflects a better understanding of the functional adaptation of bones. Most of the early investigations concentrated on the mechanical properties of cortical bone $[7,10]$. The importance of mechanical behaviour of cancellous bone is reflected in the understanding of the effects of metabolic and degenerative diseases, such as osteoporosis and osteoarthritis, on bone strength. Cancellous bone has a more porous structure than cortical bone. As a result of a greater surface area, cancellous bone has a higher metabolic (turnover) rate and is more responsive to changes in mineral storage [11]. Therefore, bone loss, caused by diseases such as osteoporosis, affects cancellous bone more quickly than cortical bone. The hip and the vertebrae, which consist mainly of cancellous bone, are two common areas where osteoporotic fractures occur. Also the proximal femur (upper femoral region) is an important skeletal site for determining mechanical characteristics because this is where the bone structure and density are most critically related [9]. Cancellous bone has an irregular structure of inter connecting plates and columns, like a porous structure, called trabeculae. The unique trabecular architecture of the proximal femur is shown in Fig. 1.

It has been well established that relationships exist between apparent density, compressive strength and elastic modulus of cancellous bone. Although the cancellous bone in the proximal femur is highly anisotropic, linear correlation has been found between compressive strength and modulus of elasticity $[12,13]$. Bone anisotropy is characterized by the organization and the orientation of bone architecture in the direction of loading and it can have a major effect on the determination of mechanical properties. Power function relationships, which are quite close to a linear relationship, have been found by other studies [14-16]. A positive relationship of compressive strength and elastic modulus to apparent density of cancellous bone has also been reported $[13,17,18]$. The correlation between mechanical properties and apparent density favours the use of a power function instead of a linear function. Moreover,

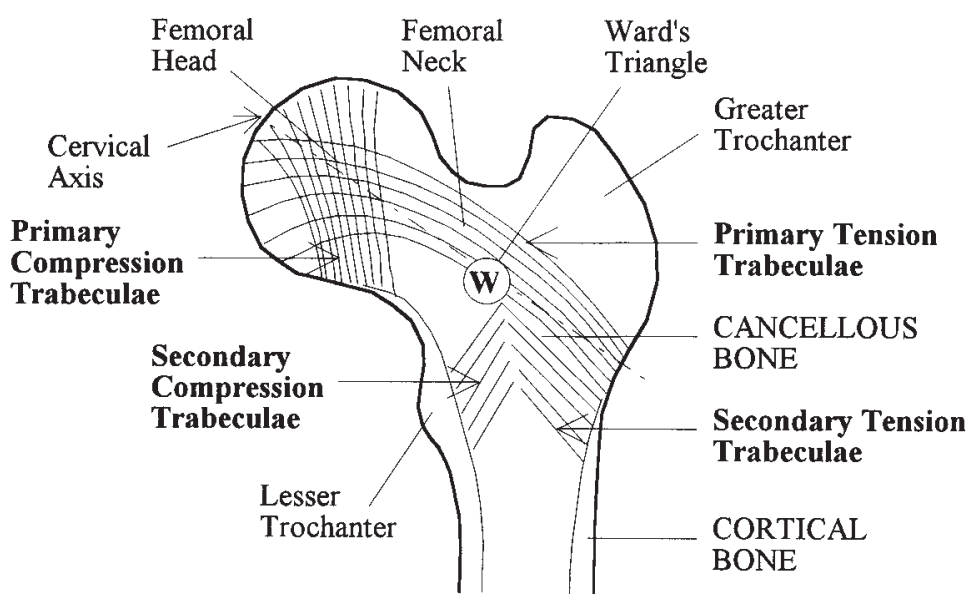

Fig. 1 Bone structural distribution and trabecular orientation of a proximal femur [9] 
compressive strength has been shown to have better correlation with apparent density than modulus of elasticity $[16,18]$. However, comparison between different studies shows an immense variation in the determination of mechanical properties $[\mathbf{1 3}, \mathbf{1 4}]$. There are several factors that may explain this large variation. Certain formulae for characterizing homogeneous and isotropic materials may not be appropriate since bone is a composite and anisotropic material [7]. In addition, the distribution of strength and density in the bone varies according to anatomical location, such as cancellous bone of the proximal femur (Fig. 1). Other contributions to the variation include the non-physiological boundary conditions of the bone specimen and the effect of bone specimen geometry in mechanical testing $[\mathbf{1 9}, \mathbf{2 0}]$. Also, the accuracy of mechanical testing is limited by the size of the bone specimen which requires meticulous preparation.

Bone densitometry is primarily used for the diagnosis of low bone mass or osteoporosis based upon density measurements of cancellous bone at a specific location such as the calcaneus (heel), forearm, hip, spine and tibia. BMD at the femoral neck is usually used by clinicians as an indication of bone strength [9]. It has been established that low BMD obtained from densitometry is associated with increased risk of fracture [21]. In general, BMD has been found to decline linearly after the age of 55 years [22]. Since densitometric measurements are very site specific, the measurement at one location does not reflect the measurement at another. The degree of bone loss may vary at different locations within the patient [9]. The measurement of BMD is also affected by the thickness of soft tissue and fat around the measured site, as well as the bone distance from the table and its positioning. Moreover, an optimal site for the assessment of bone density has not been established for the prediction of fracture risk [23]. Establishing relationships between densitometric measurements, normally between different measuring techniques such as DXA, QCT and QUS, has been the subject of more recent investigations due to the wider availability of clinical densitometry equipment [24-26]. However, no conclusive findings have been reported on the most effective technique for evaluating bone strength and fracture risk. Apart from BMD, which has been reported to account for approximately $70-80$ per cent of the bone strength [9], bone quality and bone architecture are also responsible for the loss of bone strength. In addition, densitometric measurements of a location give only an average mineral density over a region of interest (ROI) regardless of the trabecular orientation and the density variation within.

Bone densitometry is, at present, the only in vivo method of evaluating bone strength, and as a result, an ever increasing interest in bone strength, and the correlation between densitometric measurements and mechanical properties, has been generated. Investigations into the relationship between densito- metric measurements and mechanical properties of cancellous bone have had contrasting results [27-30]. The most basic comparison between apparent density and BMD produces correlations ranging from moderate to high. Relationships of BMD with compressive strength and modulus of elasticity share a similar correlation characteristic. It has also been reported that both the mechanical properties and densitometric measurements have a large overlap between healthy and diseased bones $[\mathbf{1 5}, \mathbf{2 1}]$.

\section{DRILLING OF BONE}

Bone densitometry and determining mechanical properties of cancellous bone can be assumed to represent two extreme methods of evaluating bone strength. Bone drilling measurements using small diameter drill bits have been proposed as an alternative method for evaluating bone strength $[31,32]$. The level of resistance produced by bone drilling can indicate not just the density, but also bone orientation and quality. In addition, drilling force profiles produced are only limited by the drilling bit diameter, and therefore, provide better spatial resolution or accuracy than densitometric and mechanical methods. Correlation between drilling data and mechanical properties is not well established, although it can be expected to have certain similarities to the correlation between penetration strength and ultimate compressive stress reported by Hvid et al. [33]. Penetration strength is obtained from forces which are generated by a needle driven at a constant feed rate and measured continuously with respect to displacement by an instrument known as an osteopenetrometer. It has been found that, using a power function, average penetration strength has a good linear correlation with the ultimate compressive stress [33]. Significant linear relationships of penetration strength with densitometric measurements and mechanical properties of human proximal tibiae have also been found $[34,35]$.

A linear relationship has been found between triaxial compressive strength and drilling strength (defined as the ratio of energy input to volume of bone broken) for both human tibial cortical and femoral head cancellous bones $[31,36]$. However, no statistical significance has been presented for this linear relationship. In addition, hardness has been shown to have no relationship with drilling strength [31].

Drilling force is normally quantified in terms of an average value. However, this type of measurement is not applicable to cancellous bone, especially in the proximal femur, due to its large variation in both bone architecture and density within the bone. A continuous measurement of drilling force would therefore be more useful to represent changes in density, and hence bone strength, along a specific drilling trajectory. Continuous changes in drilling forces in the femoral head (human) have been

Proc Instn Mech Engrs Vol 214 Part H 
presented by Chagneau and Levasseur [32] using a method called dynamostratigraphy which advances a drill bit at a constant rate. The forces measured by dynamostratigraphy show clear changes in the resistance of cancellous bone across the femoral head at different drilling trajectories. Although punching tests have also been conducted, correlation between drilling and punching forces has not been presented [32]. When compared with drilling, punching tests have been found to produce higher forces. This could be attributed to the deformation forces associated with compliance of the porous cancellous bone structure, during punching, before failure by shear.

The limited literature on bone drilling for bone strength evaluation of cancellous bone indicates a need to investigate the possible correlation of drilling data, such as force and penetration rate, with densitometric measurement or mechanical properties of bone. Therefore, the aim of this investigation is to establish a preliminary relationship between drilling forces and densitometric measurements. Both bone drilling and bone densitometry are extensively used in orthopaedic surgery and clinical evaluation of bone strength respectively. As a result, an alternative and/or complementary method of evaluating bone strength can be developed. This will lead to the possible development of a diagnostic tool for bone strength. The site chosen for the investigation is the proximal femur due to its unique and critical relationship between bone architecture and bone density of cancellous bone [9]. In addition, osteoporotic fractures are often associated with hip fractures, normally at the femoral neck.

\section{EXPERIMENTAL METHOD FOR DRILLING}

The drilling experimental set-up, shown in Fig. 2, for carrying out drilling tests consists of a drill feed unit, a bi-directional force sensor, a quick mount drill holder and a bone holder. The drill feed unit provides a constant feed rate through a ballscrew driven by a stepper motor. Measurement of drill feed displacement is by means of a linear potentiometer, while drilling force measurement is obtained from the change in resistance of strain gauges, arranged in Wheatstone bridge configuration, on a cantilever plate. In order to reduce/eliminate noise and avoid aliasing, the analogue measurements of feed displacement and force are filtered using fourth-order analogue Butterworth filters.

The drill holder provides a mounting for an air drill, and has a drill bit guide which is used to prevent drill bits from deflecting in order to maintain the desired drilling trajectory. The use of an air drill complies with current practice in orthopaedic surgery. For experimental purposes, industrial air drills have been used. The drill holder is designed to withstand sterilization by steam (autoclaving) which is readily available in hospitals and is relatively inexpensive. The bone holder clamps the bone to be drilled rigidly at the top. It also provides the flexibility of drilling at different linear positions along the horizontal and vertical planes. An additional plate with angular adjustment on the bone holder is used to position the proximal femur appropriately for drilling.

Controlled drilling experiments were performed at the proximal end of three fresh porcine femurs (butcher specimen). The porcine femurs, which were stripped of all soft tissue, were clamped rigidly on to the bone holder in accordance with the section to be drilled, as shown in Fig. 3. The drilling trajectories for the experiments were dependent upon the site of drilling. The trajectories were in two directions: (1) in the anterior-posterior (AP) direction as shown in Fig. 3a and (2) in the direction parallel to the cervical axis as shown in Fig. 3b. Drilling in the AP direction was applied to sections at the greater trochanter and the femoral head, as shown in Fig. 4a. The drilling trajectories in the direction of the cervical axis were positioned approximately $45^{\circ}$ from the shaft axis. These trajectories also included positions parallel

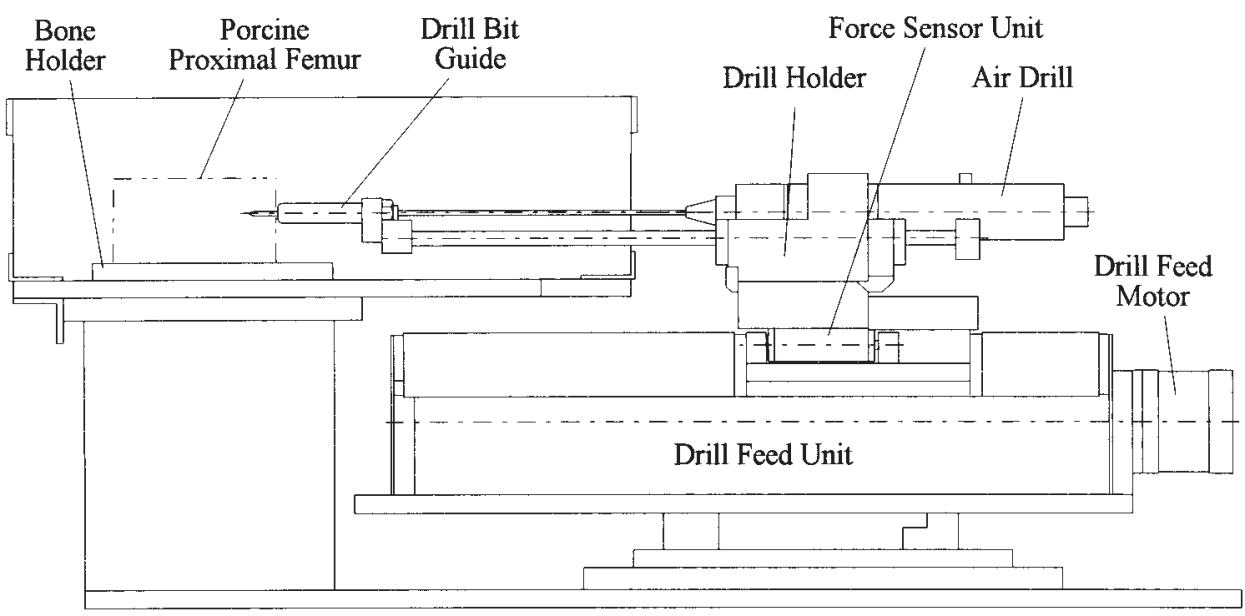

Fig. 2 Experimental set-up for drilling porcine proximal femurs 

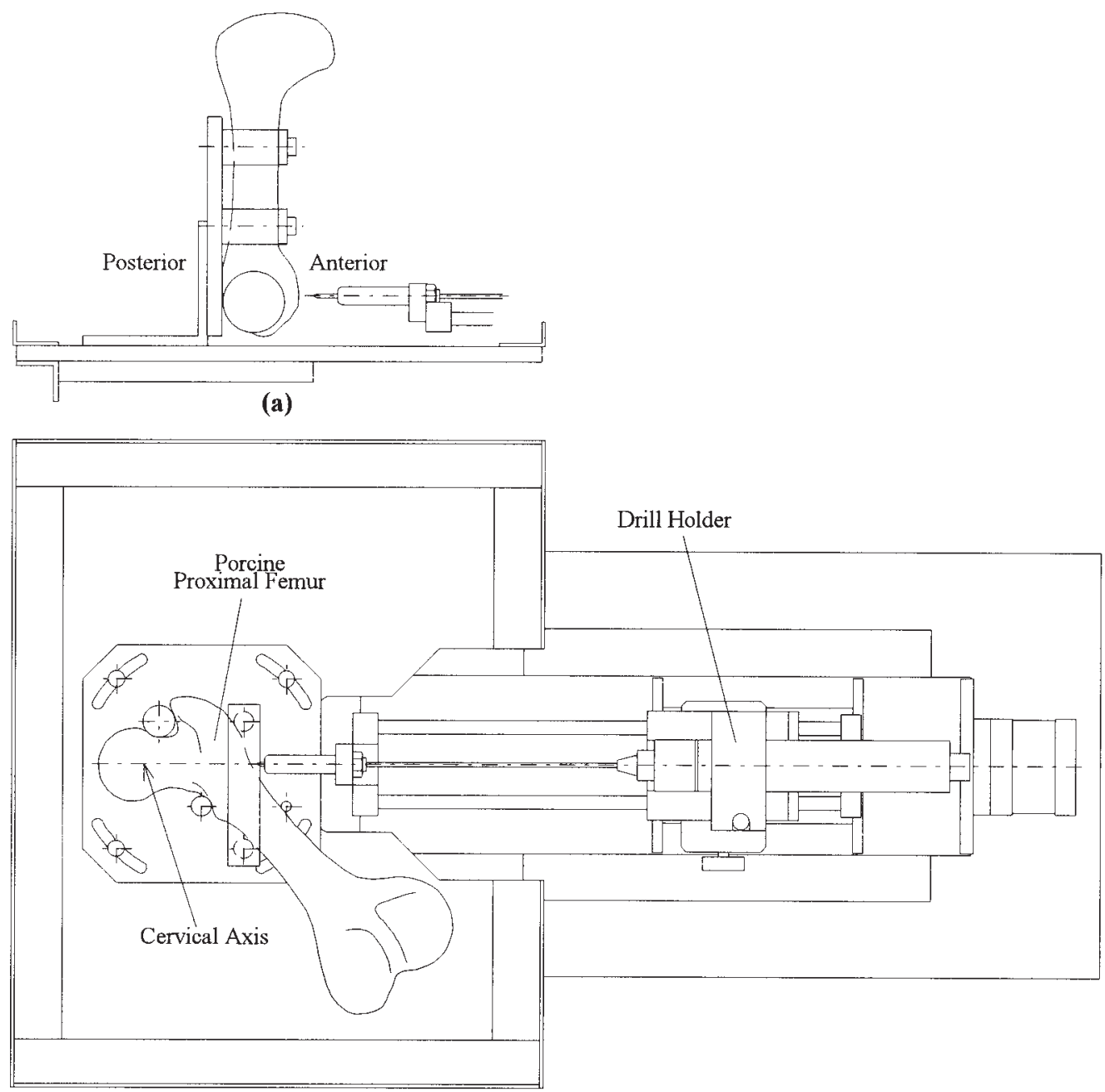

(b)

Fig. 3 Experimental set-up for drilling porcine proximal femurs: (a) in the AP direction, and (b) in the direction of the cervical axis

to the cervical axis in both the horizontal (lateral) and vertical (AP) planes, as shown in Fig. 4b.

A long series standard metal-cutting (industrial) twist drill bit with diameter $2.5 \mathrm{~mm}$ was used in the drilling experiments. With long drill flutes the industrial bit was found to exhibit lower friction between the drill bit and the bone during drilling compared with a surgical drill bit, which has short drill flutes. The use of an industrial drill bit in the evaluation of bone strength is also in line with current literature [31]. The drill bit was driven at a feed rate of $90 \mathrm{~mm} / \mathrm{min}$ and at a rated free rotational speed of $1000 \mathrm{r} / \mathrm{min}$. This rated rotational speed is within the range of rotational speed of most surgical drills. The intention is to use a mechatronic drill unit to measure the drilling force profile in practice, thus the speed of rotation and feed rate can be pre-set at those specified. It should, however be noted, that different drilling rotational speeds and feed rates will provide different drilling force amplitudes.

\section{BONE DENSITOMETRY}

In order to determine the contribution of BMD to the drilling forces, established densitometric measurement of BMD is utilized for correlation purposes. BMD (in $\mathrm{g} / \mathrm{cm}^{2}$ ) of porcine femurs was measured using a Lunar DPX-alpha dual X-ray absorptiometry (DXA or DEXA) instrument. The scanning resolution of the Lunar DPX-alpha is given as 167 lines per 7.87 inches (200 $\mathrm{mm})$ by 150 sample points per 7.09 inches $(180 \mathrm{~mm})$ which works out to be regions measuring $1.2 \mathrm{~mm}$ $\times 1.2 \mathrm{~mm}$.

The bone was placed in a supine position under approximately $15 \mathrm{~cm}$ of water to simulate body tissue around the hip. A DXA scan of the proximal femur was performed before drilling experiments were carried out. After the drilling experiments, an X-ray image was taken to identify the different drilling trajectories (or positions), and the X-ray image was subsequently used to 


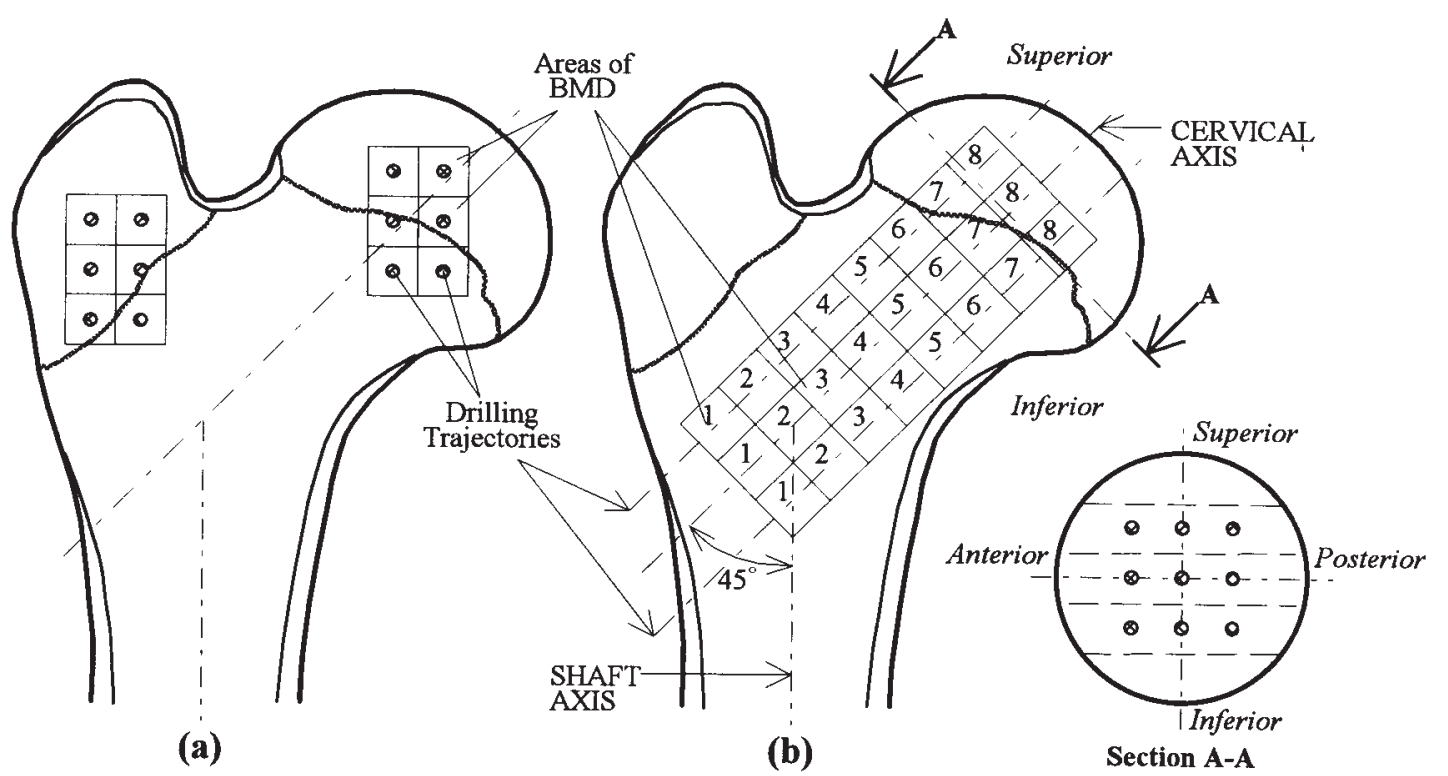

Fig. 4 Areas or ROIs of BMD and drilling trajectories of a porcine proximal femur: (a) at the greater trochanter and the femoral head and (b) parallel to the cervical axis of the proximal femur with ROI numbering

identify the areas or regions of interest (ROI) where BMD measurements were taken. The drilling trajectories and ROIs are shown in Fig. 4. Figure 4a shows the ROIs of BMD at the greater trochanter and the femoral head of the proximal femur, while Fig. $4 \mathrm{~b}$ shows the ROIs according to drilling trajectories parallel to the cervical axis. The size of each ROI was set at $6 \mathrm{~mm} \times 6 \mathrm{~mm}$ to give an area of $36 \mathrm{~mm}^{2}$.

\section{CORRELATION METHOD}

There were two types of relationship to be determined in this investigation. Firstly, an analysis was carried out to establish a correlation between the average drilling forces and the BMDs in the direction of the DXA scan (AP direction), which involved sites at the greater trochanter and the femoral head. The average drilling forces were calculated from the first peak at the start of drilling to the last peak just before drill bit break-through. Although drilling in the AP direction is not performed in orthopaedic surgery, this analysis was carried out to investigate the relationship between drilling force and BMD in order to provide a justification for the use of drilling force measurements in the direction of the cervical axis in the evaluation of bone strength.

The second relationship to be determined was the correlation between the drilling forces in the direction of the cervical axis and the BMDs in the AP direction. In order to match the ROIs obtained from bone densitometry for this second type of correlation, the profiles of drilling force were divided or discretized into sections or sectors that corresponded to the BMD ROIs. The drilling forces within these sectors were taken as an average value before correlating them to the BMD values. The locations of the specific ROIs for both the drilling force and the BMD were matched as closely as possible based on X-ray and BMD images to minimize matching errors of the drilling force. These errors could be assumed to be small since a relatively large number of drilling force values was taken for averaging.

The correlation between average drilling forces and BMDs was examined using linear regression analysis according to the least-squares method. The statistical significance of the relationship was given by the coefficient of correlation/determination.

\section{RESULTS}

The results are presented in four sections. Section 6.1 presents the correlation between average drilling forces in the AP, or DXA scanning, direction and BMD measurements. Average drilling force in the cervical axis direction and BMD profiles according to BMD ROIs are given in Sections 6.2 and 6.3 respectively. The correlation between average drilling forces in the cervical axis direction and BMDs is presented in Section 6.4.

\subsection{Correlation in the anterior-posterior (AP) direction}

Significant linear relationships $(P<0.005)$, shown in Fig. 5, were found between the average drilling forces and the BMDs in the AP direction at both the greater trochanter and the femoral head sites. The greater trochanter site showed a better linear correlation $\left(r^{2}=0.85\right.$ or $\left.r=0.92\right)$ compared with the femoral head 


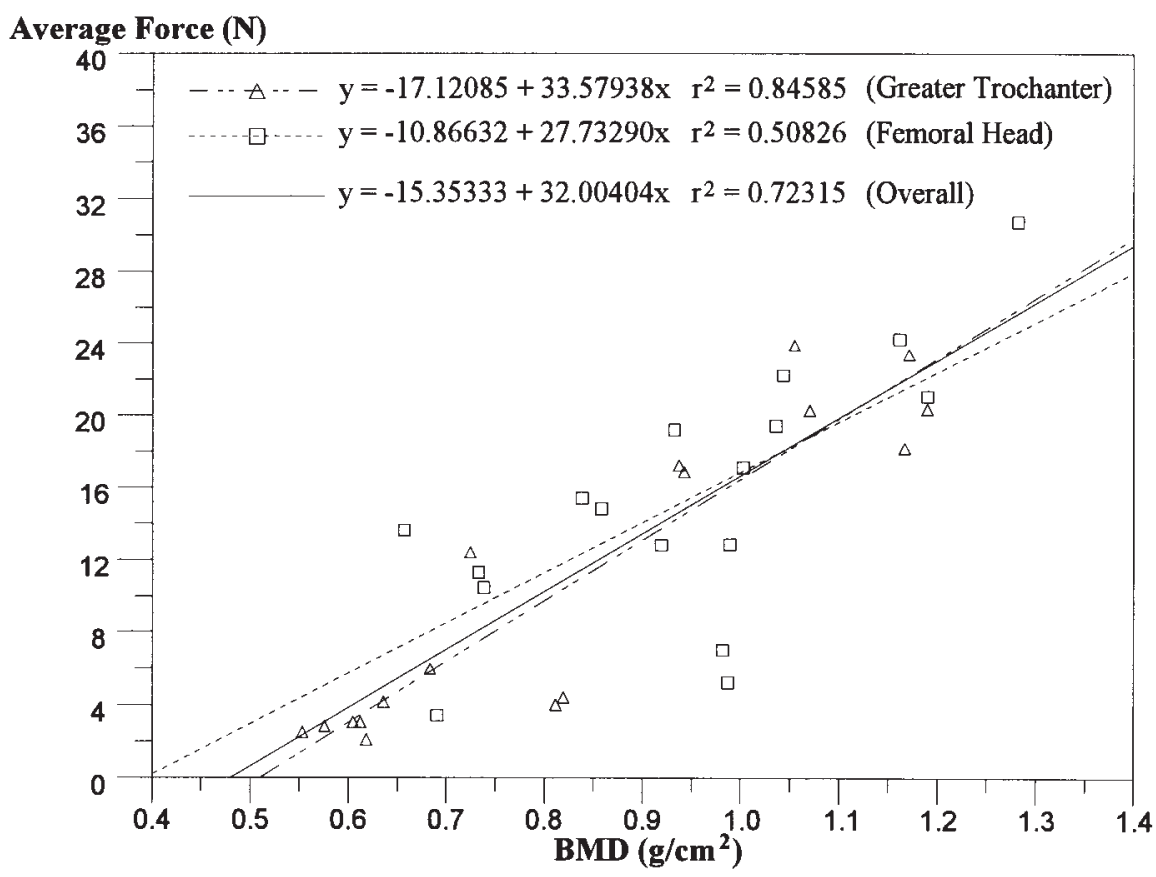

Fig. 5 Linear regression between average drilling forces and BMDs in the AP direction of porcine proximal femurs at the greater trochanter and the femoral head $(P<0.005)$

site $\left(r^{2}=0.51\right.$ or $\left.r=0.71\right)$. There is also a difference between the two slopes of correlation. The combination of the two sets of data produced a linear correlation with a good correlation coefficient $\left(r^{2}=0.72\right.$ or $\left.r=0.85\right)$. Although the number of measurements was limited, the correlations clearly showed the existence of a trend related to the evaluation of bone strength. However, difficulty encountered in matching the centre of a drill hole to the ROI might have introduced errors to the correlation.

It must also be noted that a component of the measured drilling force is a frictional force. Since the bone is an elastic material, some of the deformation around the drilled hole will recover sufficiently and cause friction. The amount of friction between the drill bit and the bone was found to be relatively small, at an average of approximately $0.3 \mathrm{~N}$ at the maximum depth of drilling. The frictional forces were obtained by advancing the drill bit into the drilled hole.

\subsection{Profiles of the average drilling force in the direction of the cervical axis}

The drilling trajectories in the cervical axis direction were classified into superior, cervical axis and inferior sections, shown in Fig. 6a. These sections were further divided into anterior, lateral-medial and posterior zones, shown in Fig. 6b. The drilling trajectories were approximately $6 \mathrm{~mm}$ apart. Since a drill bit of diameter $2.5 \mathrm{~mm}$ was used (resulting in a least distance of $3.5 \mathrm{~mm}$ between the walls of the drilled holes) and bone material is removed and not deformed during drilling, it is not expected that any significant interaction effects are introduced into the results. Similar distances between drilled holes have been used by other researchers [32]. Typical average drilling force profiles corresponding to the ROIs of BMD (as indicated in Fig. 4b) are presented in Fig. 7. The mean values (indicated by continuous lines) were calculated from the average drilling forces of anterior, lateral-medial and posterior zones. When drilling in the superior section, the force profiles for the anterior and the lateral-medial zones, shown in Fig. 7a, were different in terms of force magnitude and distribution of strength. The average drilling profile for the posterior zone was not included because the drilling trajectory at this position was severely diverted as the drill bit penetrated the femoral head.

The average force profiles at all three zones of the cervical axis section were highly consistent. Also, the average force profiles at the cervical axis (Fig. 7b) and the inferior (Fig. 7c) sections were shown to share many similarities in the anterior and lateral-medial zones. However, the drilling forces were generally lower in the inferior section. The forces in the intertrochanteric and femoral neck regions for the anterior and lateral-medial zones were found to be relatively low. The highest drilling forces were obtained from the region of the femoral head.

The presence of red marrow in the cervical axis and the inferior sections may account for the low drilling forces in the intertrochanteric region. In addition, the effects of trabeculae orientation in the direction of the cervical axis coupled with low bone density may partly explain the low drilling forces in the femoral neck region.

As explained previously, a small component of the 


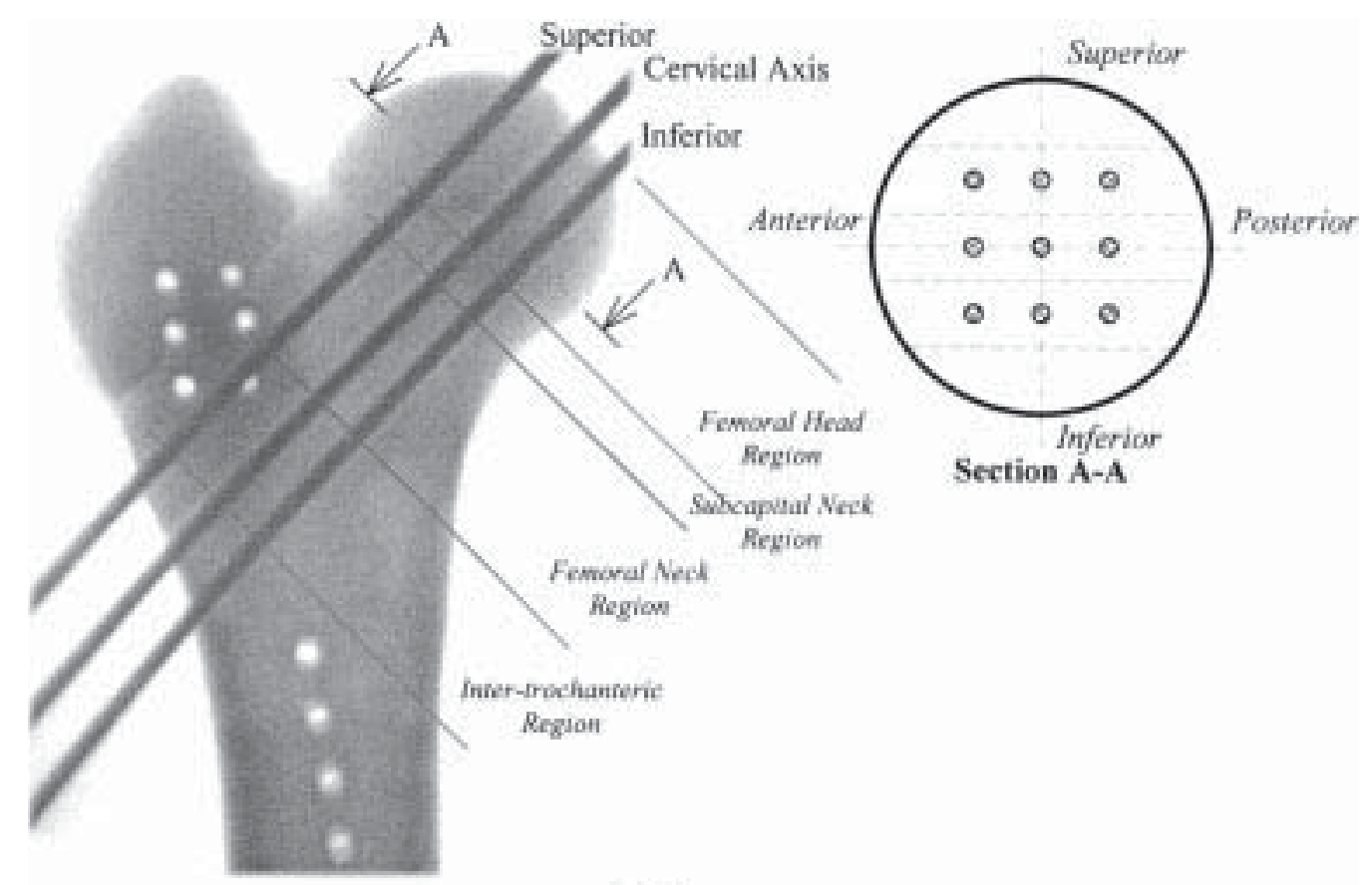

(a)

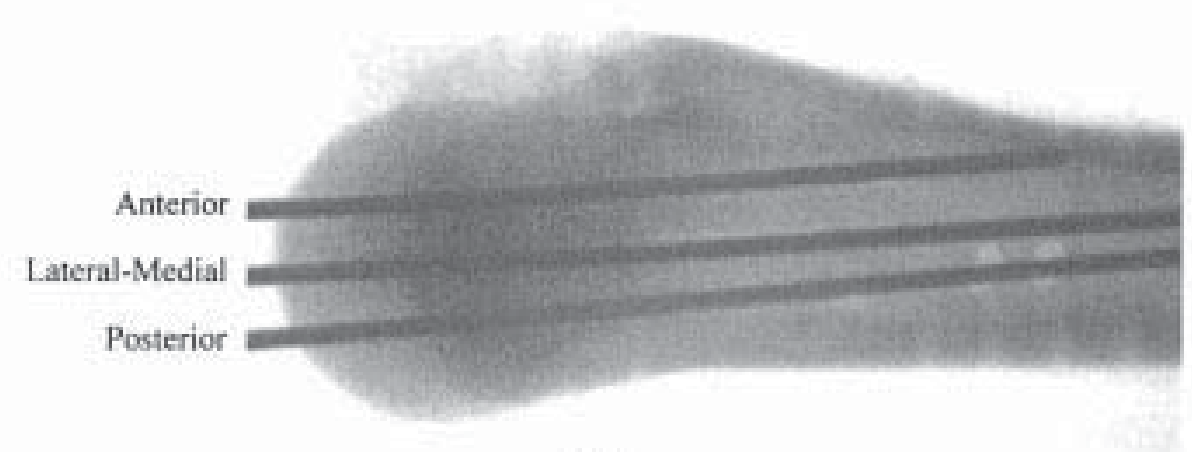

(b)

Fig. 6 X-ray images of a porcine proximal femur showing drilling trajectories in the direction of the cervical axis: (a) AP view, (b) lateral view

measured drilling force is the frictional force. The frictional forces between the drill bit and the bone at different drilling trajectories increased with the depth of drilling. The maximum average frictional force was found to be less than $0.8 \mathrm{~N}$ at the maximum depth of drilling. This value of friction, which is of low magnitude, may have little effect on the drilling force at the femoral head region. However, the effect of friction can be considerable in the regions of the intertrochanter and the femoral neck because the drilling forces obtained in these regions have been found to be relatively low.

\subsection{Profiles of the BMD}

The levels of BMD of a porcine proximal femur at the ROIs located superior to (above), inferior to (below) and on the cervical axis, as indicated in Fig. 4b, were found to be different. Typical profiles of the BMD (in $\mathrm{g} / \mathrm{cm}^{2}$ ) are shown in Fig. 8, which as in Fig. 7 includes an indication of regions of the proximal femur corresponding to the ROIs. At the superior section to the cervical axis, the BMDs around the intertrochanteric region were high, or the highest. Among the lowest of all BMDs obtained were from ROIs around the regions of the femoral neck.

The BMDs in the intertrochanteric region of the cervical axis were found to be high, while the BMDs were at the lowest in the region of the femoral neck. After this region, the BMD increased to a peak at ROIs around the centre of the femoral head before it decreased near the edge of the femoral head.

The BMDs at the intertrochanteric region up to the subcapital femoral neck region of the inferior section were found to be the lowest when compared with the two previous sections. In the centre of the femoral head region, the BMDs were at the highest and the profile of BMD was similar to the BMD profile at the cervical axis section. 


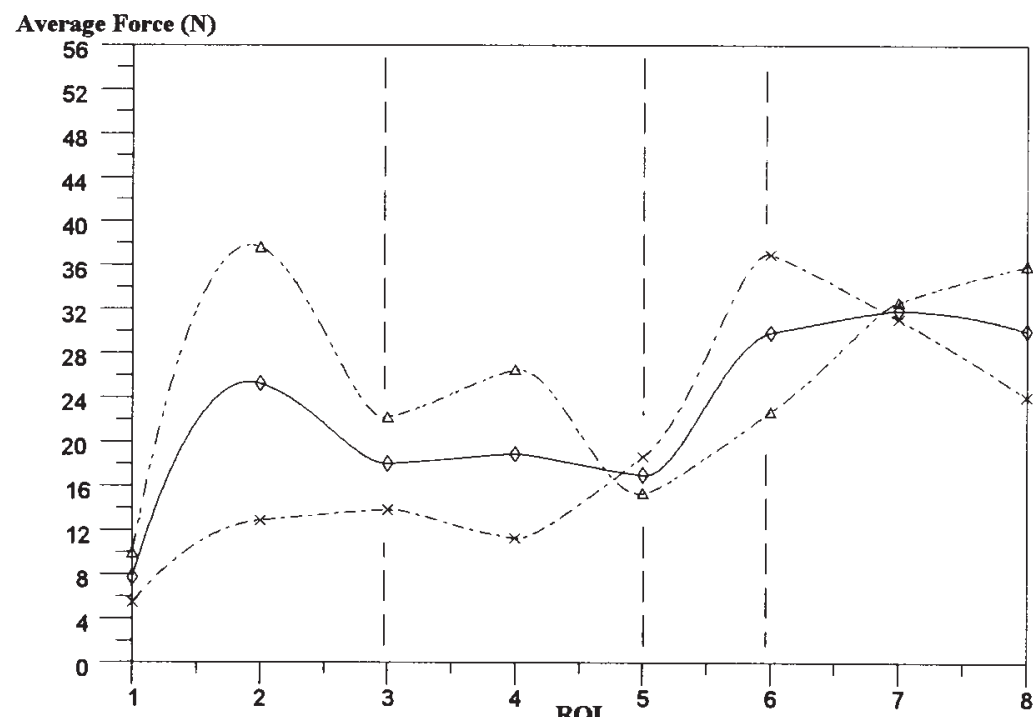

Average Force (N)

(a) SUPERIOR Section

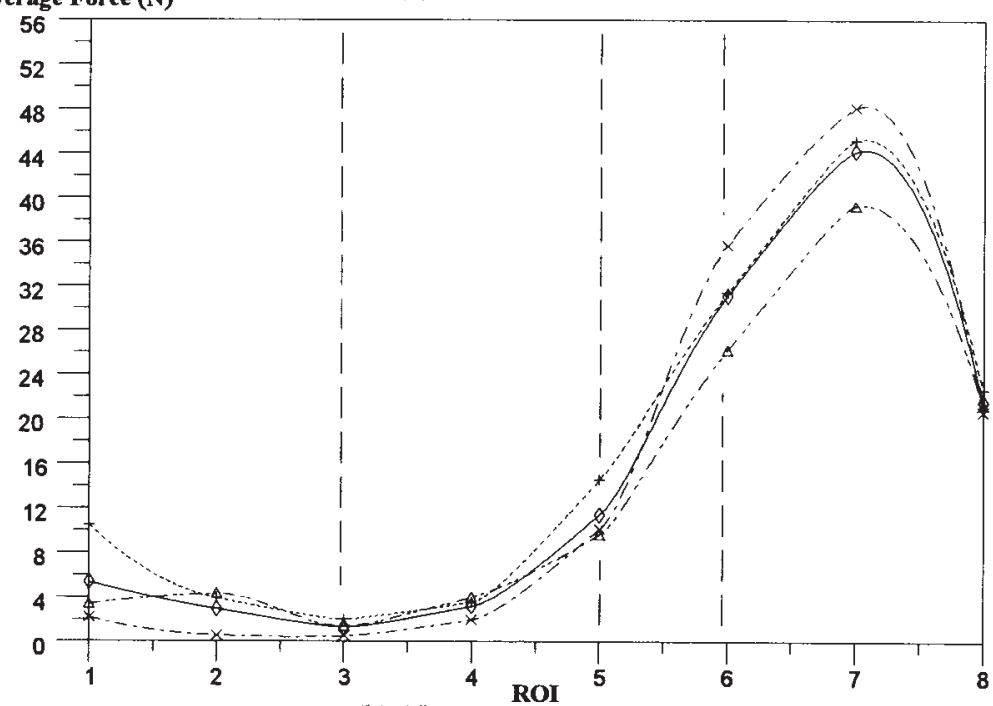

$$
\begin{aligned}
& --\Delta-- \text { Anterior } \\
& --\star-- \text { Lateral-Medial } \\
& \cdots+- \text { Posterior } \\
& \square \quad \text { Mean }
\end{aligned}
$$

Average Force (N)

(b) CERVICAL AXIS Section

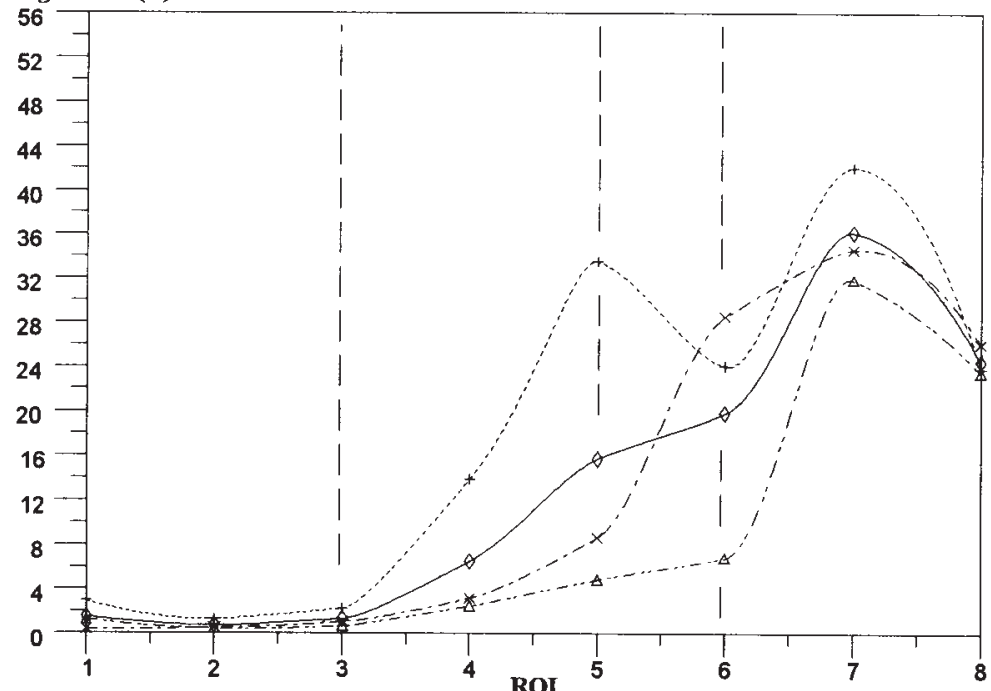

(c) INFERIOR Section

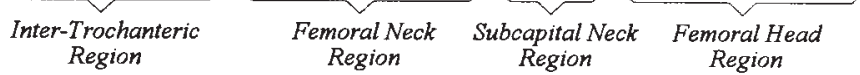

Fig. 7 Typical profiles of average drilling forces with respect to ROIs 


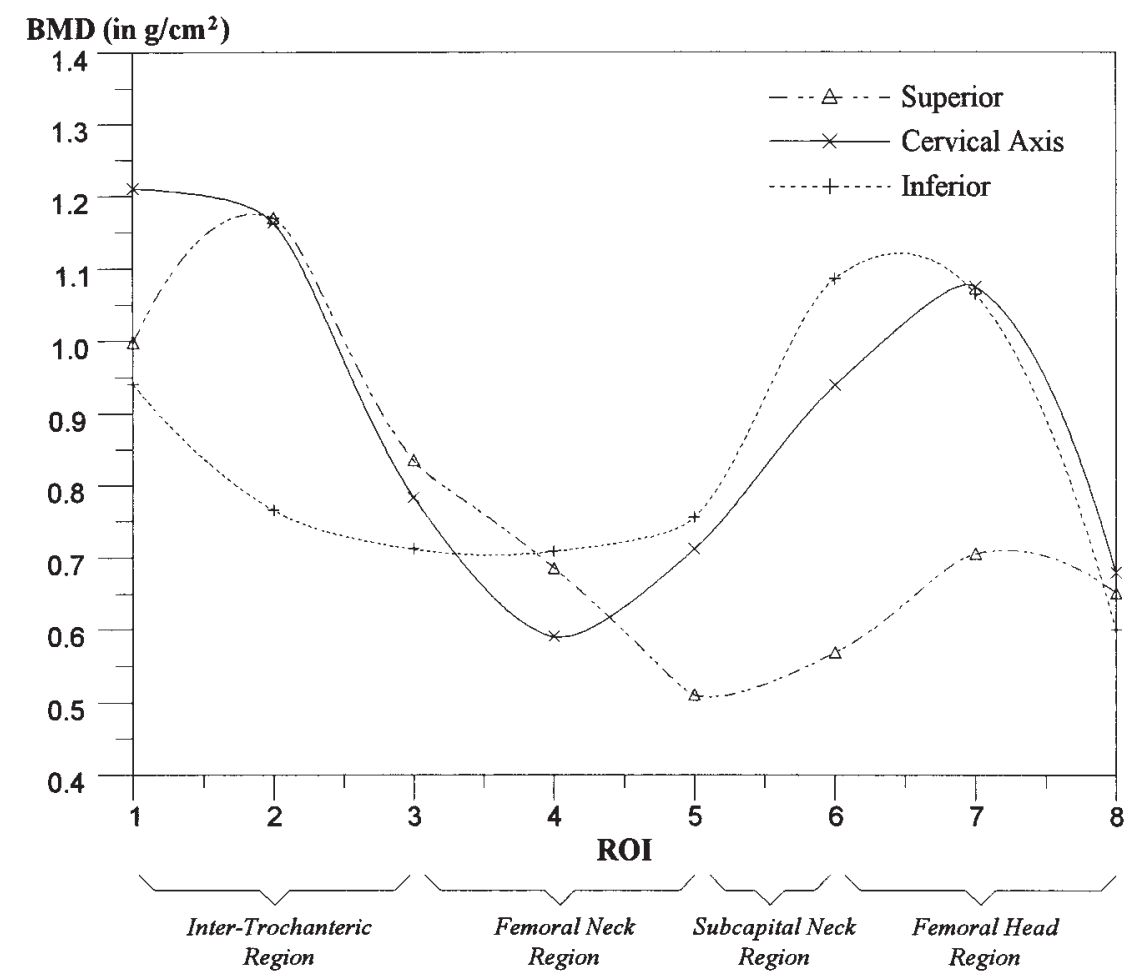

Fig. 8 Typical profiles of BMDs in $\mathrm{g} / \mathrm{cm}^{2}$ with respect to ROIs as indicated in Fig. $4 \mathrm{~b}$

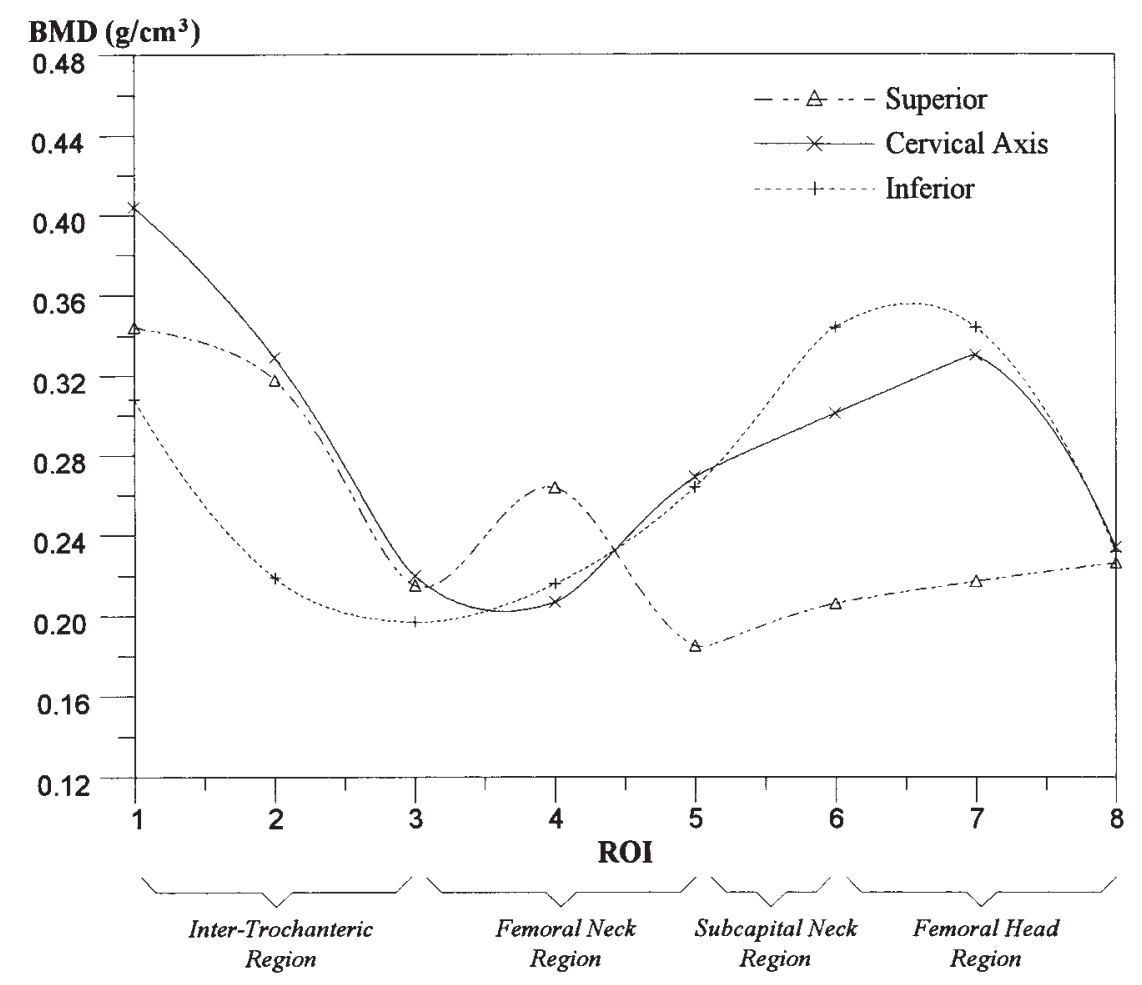

Fig. 9 Profiles of BMDs in $\mathrm{g} / \mathrm{cm}^{3}$ with respect to ROIs as indicated in Fig. 4b

The inclusion of bone thickness to obtain BMD in $\mathrm{g} / \mathrm{cm}^{3}$ at the same ROIs as those in Fig. 8 produced different BMD profiles. Figure 9 shows the new BMD profiles. The inclusion of bone thickness allows for the variation of the cross-sectional geometry of the proxi- mal femur to be considered. A notable change can be seen in the regions of the intertrochanter and the femoral neck at the superior section. The significance of including bone thickness will be evident in the correlation between BMDs and average drilling forces 
in the cervical axis direction, as presented in Section 6.4.

The cervical axis and the inferior sections (Figs 8 and 9), from the femoral neck region to the femoral head region, are shown to be the most reliable in producing a consistent BMD profile. Although differences in BMDs may be seen to represent a variation in bone strength according to the location of the proximal femur, the results must be treated with care. This is because the BMD only represents an average mineral density at a specific ROI without considering the bone density and structure within. In the extreme superior and inferior sections to the cervical axis, the BMDs may have been largely affected by the outer layer of cortical bone.

\subsection{Correlation in the direction of the cervical axis}

By comparing the average drilling forces and the BMDs shown in Figs 7 and 8 respectively, the correlation of the average forces in the cervical axis direction and the BMDs (in $\mathrm{g} / \mathrm{cm}^{2}$ ) in the AP direction can be expected to show some mixed relationships. This is due to the measurement of BMD as an average value at a specific ROI, as mentioned in the previous section, while the average drilling force represents the local variation in bone strength or mass. Also, the direction of drilling was perpendicular to the DXA scanning (or AP) direction. It should, however, be noted that there is a good relationship at the femoral head where the bone density is more consistent in both drilling directions.

In order to minimize the correlation error, the average forces and the BMDs of the first and the last ROIs, which are located near the edges of the intertrochanteric and the femoral head regions respectively, were omitted. Comparison using Figs 7 and 8 of average drilling forces and BMDs respectively, provided some indication why mixed relationships were obtained.

In the superior section to the cervical axis, the average drilling force profiles (Fig. 7a) had a different trend to the BMD profile (Fig. 8). As mentioned in Section 6.2, the variation of average forces between the anterior and the lateral-medial zones, as shown in Fig. 7a, was found to be relatively large. In addition, BMDs at the femoral head region of the superior section, as shown in Fig. 8, were lower than the femoral neck region in part, which was not the case for the average forces (Fig. 7a). As a result, no significant relationship was found between the average forces and BMDs in the superior section at the femoral neck and the femoral head regions. However, in the intertrochanteric region, there is a similar trend between the average force profile in the superior section (Fig. 7a) and the BMD profile (Fig. 8). This may reflect that the bone density in the intertrochanteric region of the superior section is more consistent. The following discussion regarding the correlation between average drilling forces and BMDs will refer only to the cervical axis and the inferior sections in the regions of the femoral neck to the femoral head, as there is greater area of correlation. Due to the drilling trajectory being $45^{\circ}$ to the femoral shaft axis, the ROIs in these two sections are mostly located in the regions of the femoral neck and the femoral head, as shown in Figs $4 \mathrm{~b}$ and $6 \mathrm{a}$.

It was found that a correlation $(P<0.01)$ was present in the regions of the femoral neck to the femoral head in the cervical axis and inferior sections of the proximal femur, as shown in Fig. 10. The best correlation was found in the lateral-medial zones where the average forces were most consistent with the BMDs, as shown in Figs $7 \mathrm{~b}$ and $\mathrm{c}$ and Fig. 8. Larger spread of the average forces was observed in the anterior and posterior zones which has affected the correlation, especially at the inferior section. In addition, the ratio between the highest and the lowest values of BMD was much lower than that of the highest and lowest average drilling forces.

The use of bone cross-sectional thickness to obtain $\mathrm{BMD}$ in $\mathrm{g} / \mathrm{cm}^{3}$ has produced an improvement in the correlation coefficient of the relationships, as shown in Fig. 11. The best improvement in the correlation was found in the posterior zones and the mean values.

For the cervical axis and the inferior sections, the low average drilling forces in the femoral neck region correspond with a minimum level of BMD of the bone. However, the BMD levels were extremely high in the intertrochanteric region, especially in the cervical axis section, as opposed to the low average forces. This would possibly mean that the cortical shell at this region accounted for the majority of the BMD levels. Hence, the thickness of the cortical bone in this region had a significant effect on the BMD measurement, and as a result, the BMD did not indicate the actual strength of the cancellous bone within. Meanwhile, the peak of average drilling force in the femoral head region corresponds to the peak in BMD, and the average force profiles and the BMD profiles have similar trends. Therefore, BMD measurements in this region could give an indication of bone strength.

\section{DISCUSSION}

Most of the investigations in bone drilling share common goals of in vivo evaluation of bone strength and assessment of the effects of metabolic diseases on bone strength. There have been very few investigations related to the drilling of the proximal femur. The changes in the drilling forces, indicated by this investigation and by Chagneau and Levasseur [32], have been shown to provide a form of quantification of the bone strength. However, relationships of drilling data with mechanical properties and densitometric measurements have not been statistically established by early bone drilling studies [31, 32]. Furthermore, drilling experiments on 


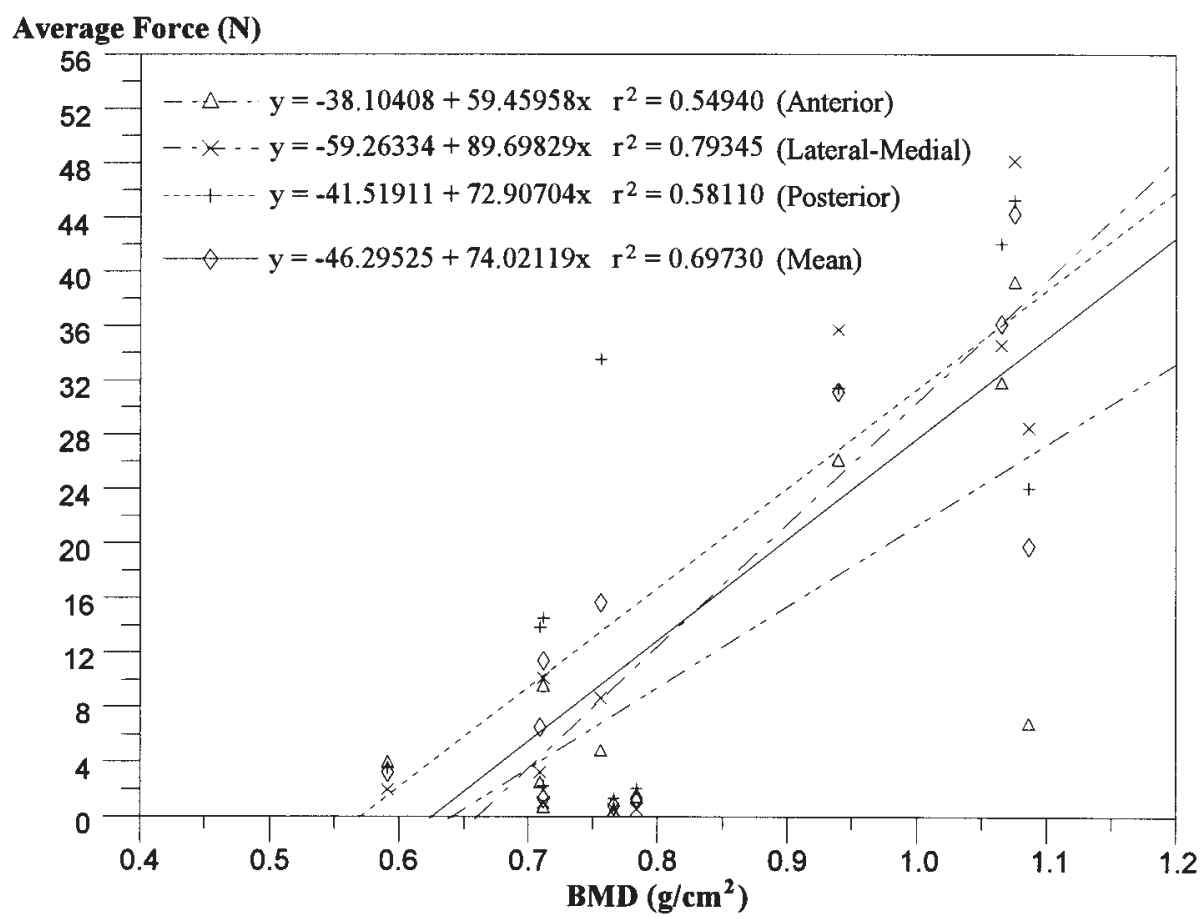

Fig. 10 Correlation between average drilling forces and BMDs in $\mathrm{g} / \mathrm{cm}^{2}$ at the cervical axis and the inferior sections in the regions of the femoral neck and the femoral head $(P<0.01)$

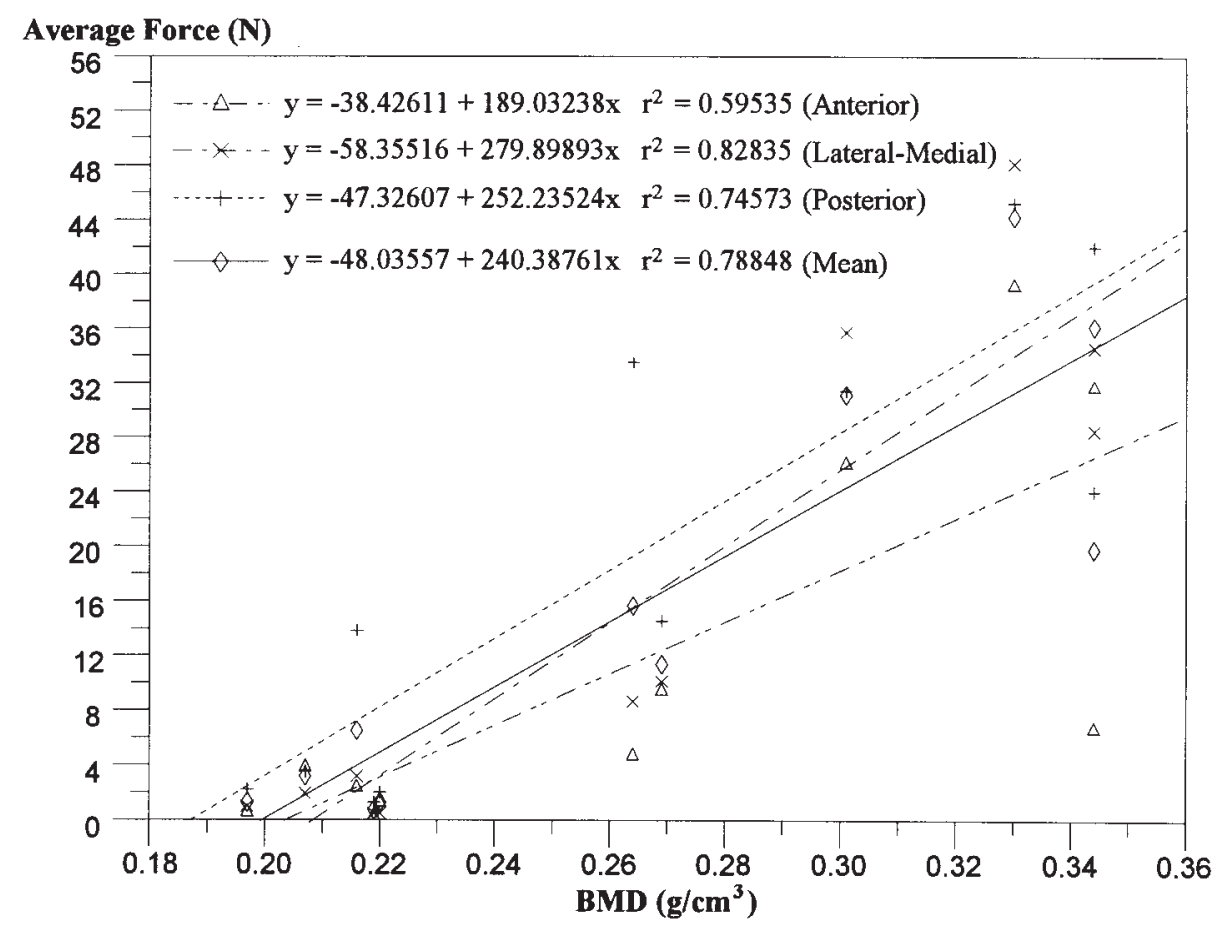

Fig. 11 Correlation between average drilling forces and BMDs in $\mathrm{g} / \mathrm{cm}^{3}$ at the cervical axis and the inferior sections in the regions of the femoral neck and the femoral head $(P<0.01)$

cancellous bone have been carried out only on femoral heads.

In this preliminary investigation, the relationship in the AP direction between the average drilling forces and the BMDs of the proximal femur has been found to be positive with a good coefficient of correlation. This is comparable with the osteopenetration results presented by Bentzen et al. [34] and Petersen et al. [35] on human proximal tibiae. Although osteopenetration strength has been found to relate to the strength of bone [33], it is not considered as part of standard surgical procedures. Unlike osteopenetration, bone drilling is extensively used 
in orthopaedic surgery. The forces involved in bone drilling are lower than the osteopenetration forces for the same feed rate. As a result, the drilling equipment will be easier to handle. The start of drilling will be easier than the direct penetration of a needle which would involve extremely high forces in order to overcome the outer layer of cortical bone. Furthermore, the friction involved in drilling, using suitable drill bits, has been shown to be minimal.

The evaluation of bone strength is not confined to the femoral neck, Ward's triangle (Fig. 1) and the femoral head. The preliminary results from this investigation show that it is possible to predict the strength of the proximal femur from the strength of the greater trochanter. This is indicated in Fig. 5, where a good linear relationship has been found between average drilling forces in the AP direction and BMDs (in $\mathrm{g} / \mathrm{cm}^{2}$ ) at the greater trochanter. A similar (linear) relationship was found by Leichter et al. [27] between overall mass density (in $\mathrm{g} / \mathrm{cm}^{3}$ ) of the greater trochanter and the average shear stress at failure (obtained from mechanical testing) of the femoral neck. Therefore, a possible relationship may be present between bone drilling and mechanical testing for the estimation of bone strength.

The preliminary results at the femoral head also show that there is a linear relationship, as shown in Fig. 5, between average drilling forces in the AP direction and BMDs. Although this correlation at the femoral head, which may be affected by the limited number of samples, is weaker than the correlation at the greater trochanter, the difference in the slope of both relationships is relatively small. As a result, a good correlation is shown by the combination of both the relationships at the greater trochanter and the femoral head. This indicates that there is a possible link in bone strength between the greater trochanter and the femoral head. In addition, it has been found that BMD accounts for approximately $70-80$ per cent of the average drilling force, as shown in Fig. 5; this is within the range of bone strength reported in many studies [9].

The drilling forces in the cervical axis direction and the BMD have been shown to be relatively low in the femoral neck region. However, the importance of the cancellous bone and the bone marrow cannot be overlooked. Martens et al. [14] conducted an experiment to evaluate the contribution of cancellous bone to the overall strength of the proximal femur. By removing cancellous bone at the centre of the intertrochanteric, femoral neck and femoral head regions, it was found that the strength of the proximal femur reduced to approximately half the original strength.

A good correlation between drilling forces in the direction of the cervical axis and BMD, as shown in Fig. 10, has been found in the regions of the femoral neck and the femoral head. Improved correlation has been shown when bone thickness is included, as shown in Fig. 11. Therefore, some of the poor relationships between mechanical properties and BMD, presented by Cody et al. [30], may be partially due to the omission of bone thickness, and also due to the inclusion of some locations of ROIs near the edges of the femoral head region. At the edges of the femoral head, the BMDs obtained are relatively low in magnitude, as shown in Fig. 8.

In addition, the correlation may have been further affected by the direction of drilling in this study or the direction of loading in the case of mechanical properties [30]. Bone densitometry can only provide BMD measurement of the proximal femur in the AP direction. Therefore, the direction of drilling or loading orthogonal to this AP direction may affect the correlation as there is a significant variation in the local strength across the proximal femur. A comparison between the correlation in the AP direction (Fig. 5) and the cervical axis direction (Fig. 10) shows a large difference in the slope of correlation. The slope of correlation in the cervical axis direction is steeper than the AP direction slope. The difference in the slope may help to explain the effects of the outer layer of cortical bone and bone thickness on the BMD measurement, and the effects of averaging drilling forces in the AP direction which reduces the contribution of high drilling forces at certain locations in the bone. Unlike forces in the AP direction, average drilling forces in the cervical axis direction approximate closely to actual drilling forces at specific ROIs.

This investigation indicates that bone drilling could be used for the evaluation of the strength of bone. Unlike mechanical compression tests, the physiological boundary conditions of the proximal femur are maintained to a certain extent during drilling experiments. The profiles of drilling forces obtained also show that bone drilling provides better spatial resolution than both the densitometric measurements and the mechanical tests. However, a number of limitations of this investigation have been identified.

The number of samples used in the correlation is relatively small and the specimens are limited to porcine bones of the same age. Using porcine bones of the same age, however, may help eliminate the age variable related to the correlation. Matching the ROIs of the average drilling force and of the BMD is difficult, and the correlation could have been adversely affected as a result of matching errors. Another limiting factor, which affects the drilling force, may be the tendency of clogging of the drill bit as a result of the large ratio between the drilling depth and the drill bit diameter. Wiggins and Malkin [3] reported that, when drilling into cortical bone using an industrial drill bit, an increase in both torque and specific cutting energy is associated with increasing depth of drilling. The drilling force may also be influenced by blood pressure in the bone during drilling. In rock mechanics, fluid pressure in the pores affects the rate of drilling and the compressive strength of rocks [31]. During the drilling experiments in this investigation, blood was seen flowing out from minute pores 
to the bone surface. This is a possible consequence of either blood boiling due to heat generated, or an increase in blood pressure due to drilling or both. Finally, the method of clamping may have introduced additional compressive stresses and altered certain trabecular structure. In spite of the limitations of this investigation, a positive relationship for the evaluation of bone strength has been found between BMD and average drilling forces.

\section{CONCLUSIONS}

In this preliminary stage of investigation it has been established that a relationship (linear) is present between average drilling forces and BMD measurements by DXA (in the AP direction). It has been shown that in the normal drilling direction (i.e. in the cervical axis direction), which is orthogonal to the DXA scanning direction, there are similar trends between drilling forces and BMD levels in the intertrochanteric region of the superior section, and also in the femoral neck to the femoral head regions of the cervical axis and the inferior sections where the bone density is more consistent. However, in contrast, in the intertrochanteric region, especially in the cervical axis section, the BMD levels were high as opposed to low average drilling forces. This could reflect that the cortical shell in this region accounts for the majority of the BMD levels. Hence the drilling force could give an indication of the local BMD in the direction of drilling.

Therefore, a mechatronic drill unit could be used in orthopaedic surgery as a matter of course, for drilling purposes and measuring the drilling forces, to provide surgeons with a quantitative evaluation of bone quality. Such evaluation is important in the absence of BMD measurements and for follow-up studies.

\section{ACKNOWLEDGEMENTS}

This research project had been partially funded by the Wishbone Trust of the British Orthopaedic Association. The authors are also grateful to Mr Graham Taylor (Consultant Orthopaedic Surgeon, Glenfield Hospital, Leicester) for his help and advice, and to Alison McKinnon (Bupa Hospital, Leicester) for carrying out BMD measurements by DXA.

\section{REFERENCES}

1 Farnworth, G. H. and Burton, J. A. Optimization of drill geometry for orthopaedic surgery. In Proceedings of the 14th International Conference on Machine Tool Design and Research, Manchester, 1974, paper 28, pp. 227-233.

2 Jacobs, C. H., Berry, J. T., Pope, M. H. and Hoaglund,
F. T. A study of the bone machining process - drilling. J. Biomechanics, 1976, 9, 343-349.

3 Wiggins, K. L. and Malkins, S. Drilling of bone. J. Biomechanics, 1976, 9, 553-559.

4 Saha, S., Pal, S. and Albright, J. A. Surgical drilling: design and performance of an improved drill. Trans. ASME, J. Biomech. Engng, 1982, 104, 245-252.

5 Ong, F. R. and Bouazza-Marouf, K. Drilling of bone: a robust automatic method for the detection of drill bit break-through. Proc. Instn Mech. Engrs, Part H, Journal of Engineering in Medicine, 1998, 212(H3), 209-221.

6 Allotta, B., Belmonte, F., Bosio, L. and Dario, P. A mechatronic tool for drilling in orthopaedics. In Proceedings of the Second International Workshop on Mechatronics in Medicine and Surgery, Bristol, 1995, pp. 92-107.

7 Evans, F. G. Mechanical Properties of Bone, 1973 (Charles C. Thomas Publisher, Springfield, Illinois).

8 Faulkner, K. G., Glüer, C. C., Majumdar, S., Lang, P., Engelke, K. and Genant, H. K. Noninvasive measurements of bone mass, structure, and strength: current methods and experimental techniques. Am. J. Roentgenol., 1991, 157, 1229-1237.

9 Wahner, H. W. and Fogelman, I. The Evaluation of Osteoporosis: Dual Energy X-Ray Absorptiometry in Clinical Practice, 1995 (Martin Dunitz, London).

10 Yamada, H. Strength of Biological Materials (Ed. F. G. Evans), 1970, pp. 19-80 (Williams and Wilkins, Baltimore).

11 Cooper, C. Bone mass throughout life: bone growth and involution. In Osteoporosis: Pathogenesis and Management (Ed. R. M. Francis), 1990, pp. 1-26 (Kluwer Academic Publishers, Dordrecht, Netherlands).

12 Brown, T. D. and Ferguson, A. B. Mechanical properties distributions in the cancellous bone of the human proximal femur. Acta Ortho. Scand., 1980, 51, 429-437.

13 Goldstein, S. A. The mechanical properties of trabecular bone: dependence of anatomic location and function. J. Biomechanics, 1987, 20, 1055-1061.

14 Martens, R., Van Audekercke, R., Delport, P., De Meester, P. and Mulier, J. C. The mechanical characteristics of cancellous bone at the upper femoral region. J. Biomechanics, 1983, 16, 971-983.

15 Hodgskinson, R. and Currey, J. D. Separate effects of osteoporosis and density on strength and stiffness of human cancellous bone. Clin. Biomechanics, 1993, 9, 262-268.

16 Keller, T. S. Predicting the compressive mechanical behaviour of bone. J. Biomechanics, 1994, 27, 1159-1168.

17 Rice, J. C., Cowin, S. C. and Bowman, J. A. On the dependence of the elasticity and strength of cancellous bone on apparent density. J. Biomechanics, 1998, 21, 155-168.

18 Brear, K., Currey, J. D., Raines, S. and Smith, K. J. Density and temperature effects on some mechanical properties of cancellous bone. Engng in Medicine, 1988, 17, 163-167.

19 Linde, F., Hvid, I. and Madsen, F. The effect of specimen geometry on the mechanical behaviour of trabecular bone specimens. J. Biomechanics, 1992, 25, 359-368.

20 Keaveny, T. M., Borchers, R. E., Gibson, L. J. and Hayes, W. C. Trabecular bone modulus and strength can depend on specimen geometry. J. Biomechanics, 1993, 26, 991-1000.

21 Marshall, D., Johnell, O. and Wedel, H. Meta-analysis of how well measures of bone mineral density predict occur- 
rence of osteoporotic fractures. Br. Med. J., 1996, 312, 1254-1259.

22 De Laet, C. E. D. H., van Hout, B. A., Burger, H., Hofman, A. and Pols, H. A. P. Bone density and risk of hip fractures in men and women: cross sectional analysis. Br. Med. J., 1997, 315, 221-225.

23 Compston, J. E., Cooper, C. and Kanis, J. A. Bone densitometry in clinical practice. Br. Med. J., 1995, 310, 1507-1510.

24 Duboef, F., Jergas, M., Schott, A. M., Wu, C. Y., Glüer, C. C. and Genant, H. K. A comparison of bone densitometry measurements of the central skeleton in postmenopausal women with and without vertebral fracture. Br. J. Radiol., 1995, 68, 747-753.

25 Moris, M., Peretz, A., Tjeka, R., Negaban, N., Wouters, M. and Bergmann, P. Quantitative ultrasound bone measurements: normal values and comparison with bone mineral density by dual X-ray absorptiometry. Calcif. Tissue Int., 1995, 57, 6-10.

26 Cunningham, J. L., Fordham, J. N., Hewitt, T. A. and Speed, C. A. Ultrasound velocity and attenuation at different skeletal sites compared with bone mineral density measured using dual energy X-ray absorptiometry. Br. J. Radiol., 1996, 69, 25-32.

27 Leichter, I., Simkin, A., Margulies, J. Y., Bivas, A., Roman, I., Deutsch, D. and Weinreb, A. Can the weightbearing capacity of the femoral neck be estimated by physical measurements on the greater trochanter. Engng in Medicine, 1988, 17, 59-62.

28 Lotz, J. C., Gerhart, T. N. and Hayes, W. C. Mechanical properties of trabecular bone from the proximal femur: a quantative CT study. J. Comput. Assist. Tomogr., 1990, 14, 107-114.

29 Rho, J. Y., Zerwekh, J. E. and Ashman, R. B. Examination of several techniques for predicting trabecular elastic modulus and ultimate strength in the human lumbar spine. Clin. Biomechanics, 1994, 9, 67-71.

30 Cody, D. D., McCubbrey, D. A., Divine, G. W., Gross, G. J. and Goldstein, S. A. Predictive value of proximal femoral bone densitometry in determining local orthogonal material properties. J. Biomechanics, 1996, 29, 753-761.

31 Karalis, T. and Galanos, P. Research on the mechanical impedance of human bone by a drilling test. J. Biomechanics, 1982, 15, 561-581.

32 Chagneau, F. and Levasseur, M. Mechanical analysis of bone structures by dynamostratigraphy. Eur. J. Mechanics A/Solids, 1992, 11, 551-571.

33 Hvid, I., Andersen, K. and Olesen, S. Cancellous bone strength measurement with the osteopenetrometer. Engng in Medicine, 1984, 13, 73-78.

34 Bentzen, S. M., Hvid, I. and Jørgensen, J. Mechanical strength of tibial trabecular bone evaluated by X-ray computed tomography. J. Biomechanics, 1987, 20, 743-752.

35 Petersen, M. M., Jensen, N. C., Gehrchen, P. M., Nielsen, P. K. and Nielsen, P. T. The relation between trabecular bone strength and bone mineral density by dual-photon and dual-energy X-ray absorptiometry in the proximal tibia. Calcif. Tissue Int., 1996, 59, 311-314.

36 Jaeger, J. C. and Cook, N. G. W. Fundamentals of Rock Mechanics, 1979 (Chapman and Hall, London). 